\title{
Lowest Astronomical Tide in the North Sea derived from a vertically referenced shallow water model, and an assessment of its suggested sense of safety
}

Cornelis Slobbe, The Netherlands, Delft University of Technology

Roland Klees, The Netherlands, Delft University of Technology

Martin Verlaan, The Netherlands, Deltares

Leendert Dorst, The Netherlands, Hydrographic Service of the Royal Netherlands Navy

Herman Gerritsen, The Netherlands, Deltares

Topic J: accurate hydrodynamics

\section{INTRODUCTION}

Water level reduction with GNSS [FIG Commission 4 Working Group 4.2 2006, Dodd and Mills 2011] requires the availability of the ellipsoidal heights of $C D$, i.e. the Lowest Astronomical Tide (LAT) as adopted by the International Hydrographic Organization [International Hydrographic Organization, 2011, Technical Resolution 3/1919]. LAT is defined as the lowest tide level to occur under average meteorological conditions and under any combination of astronomical conditions. Ideally, the ellipsoidal heights of LAT are derived from the analysis of time series of observed water levels relative to a reference ellipsoid at tide gauges, GNSS buoys, or satellite radar altimeter crosstracks. Here, radar altimeter data are crucial in case one aims to derive an area covering surface, since only these data have a homogeneous spatial coverage. In shallow water, however, the limited temporal resolution of radar altimeter data does not allow to resolve all relevant tidal constituents. Hence, in order to obtain an accurate, area covering realization of the ellipsoidal heights of LAT in these waters, LAT values determined at tide gauge stations are complemented by LAT values derived from a shallow water tide model after adding the modeled LAT values to an altimetry-derived MSL model [e.g., Simon, 2001, Turner et al., 2010] including some interpolation procedure to bridge the gap between tide gauge stations and MSL data from satellite radar altimetry. Here, the MSL represents the water level under average meteorological conditions and is identified as the model's reference surface. This procedure, however, cannot be applied in coastal regions and estuaries, since these regions lack reliable radar altimeter data (i.e. information about MSL). Here we develop an alternative procedure for LAT realization in coastal waters that does not rely upon MSL data from satellite radar altimetry. The procedure will be used in the future to realize LAT in Dutch coastal waters, the Wadden Sea, and the Western and Eastern Scheldt estuaries.

In this study, LAT will be modeled relative to a geoid, after which the ellipsoidal heights of LAT will be obtained by adding geoid heights to the modeled LAT values. The use of a geoid instead of MSL has the advantage that the former can be realized everywhere and does not leave a gap along the coast as satellite radar altimetry does. Modeling LAT relative to a geoid is realized by i) the explicit modeling of the average meteorological and steric conditions as required by the definition of LAT and ii) referencing the hydrodynamic model to the chosen geoid. Another advantage of this approach is that it is conceptually consistent; unlike MSL, both the geoid and the model's reference surface are equipotential surfaces. Moreover, this approach allows for the inclusion of temporal variations in the definition of the average meteorological conditions. The latter reason follows from a precise interpretation of the LAT definition that the average meteorological conditions in spring and those in fall should be included separately.

For the user of LAT, its definition may suggest that instantaneous water levels will hardly drop below LAT. On the other hand, it is well-known that meteorological conditions have a significant influence on the water level in the North Sea. Besides the issue of obtaining an accurate representation of the ellipsoidal heights of the LAT surface using hydrodynamic models, obtaining insight into the probability of a water level lower than LAT will be the other major topic of this paper. Similarly to Slobbe et al. [2012a], the model used in this study is the Dutch Continental Shelf Model version 5 (DCSM), which is a $2 \mathrm{D}$ tide-surge model that we extended to account for the horizontal variations in water density. 
In this article, we will first introduce the extended DCSM 2D tide-surge model and describe the data sets used in the numerical experiments. Next, we will present and discuss the results of an experiment designed to investigate the capability of the hydrodynamic model to determine LAT relative to the geoid by including the average month-to-month variations in meteorological and steric conditions. Next, we will present the probability that the instantaneous water level drops below LAT, and propose a probabilistic method to realize a Chart Datum. Finally, we conclude by emphasizing the main findings and by some concluding remarks. A more extended analysis is presented in Slobbe et al. [2012b].

\section{EXTENDED DCSM MODEL AND DATA SETS}

In this study we will model LAT relative to the European Gravimetric Geoid 2008 (EGG08) [Denker et al., 2008], which is the state-of-the-art geoid model for Europe. Furthermore, we will compute the probabilities that the instantaneous water level drop below LAT. In all our experiments, we will model the water levels with a time step of 10 minutes over the period January 1, 1984 to January 1, 2004.

\section{The extended Dutch Continental Shelf Model}

The numerical model used in this study is the extended Dutch continental shelf model (DCSM) described by Slobbe et al. [2012a] (the original DCSM model is described by Gerritsen et al. [1995], Verlaan et al. [2005]). DCSM was developed to make tide and surge forecasts over the full nodal cycle in order to support operational management of the Eastern Scheldt storm surge barrier. The model is based on the WAQUA software package [Leendertse, 1967, Stelling, 1984] for depth-integrated flow. WAQUA includes the non-linear surge-tide interaction and is based on the depth-integrated shallow water equations. DCSM covers the area of the northwest European continental shelf to at least the $200 \mathrm{~m}$ depth contour, i.e. $12^{\circ} \mathrm{W}$ to $13^{\circ} \mathrm{E}$ and $48^{\circ} \mathrm{N}$ to $62.3^{\circ} \mathrm{N}$, and has a horizontal resolution of $1 / 8^{\circ} \times 1 / 12^{\circ}$ (approximately $8 \times 9 \mathrm{~km}$ ) in longitude and latitude, respectively.

Although in the original model formulation the water density was assumed to be uniform, here we will allow for horizontal variations in water density. In the North Sea, these variations induce a 3D flow structure that cannot be handled by a 2D shallow water model. Hence, the water density is treated as a diagnostic variable computed from temperature and salinity values derived from a 3D hydrodynamic model using the international thermodynamic equation of seawater 2010 (TEOS-10) [IOC, SCOR and IAPSO, 2010]. In the model equations this contribution shows up by the depth-averaged baroclinic pressure gradient terms.

In order to obtain a unique solution of the equations, a set of boundary conditions is prescribed. Through closed boundaries, where neither inflow nor outflow can occur, the flow velocity normal to the boundary is set equal to zero. At the open sea boundaries, water levels are prescribed referring to the EGG08 geoid as discussed in detail in Slobbe et al. [2012a]. As shown by Slobbe et al. [2012a], in this way we obtain a model that provides water levels relative to the geoid. Note that in case water enters the model domain, the prescription of water level is supplemented by the condition that the velocity parallel to the open sea boundary is zero.

\section{Wind and Mean Sea Level pressure}

As meteorological input data we used the publicly available data derived during the interim reanalysis project ERA-Interim, performed by the European Centre for Medium-Range Weather Forecasts (ECMWF). ERA-Interim covers the period from January 1, 1979 onwards and provides 3-hourly grids with a spatial resolution of $1.5^{\circ} \times 1.5^{\circ}$; the data are available from the ECMWF data server. For a description of the model, the data assimilation method, and the input data sets used in ERA-Interim we refer to Dee et al. [2011]. 
Salinity and temperature fields used to compute the density variations and hence the depth-averaged baroclinic pressure gradients, are obtained from the Atlantic- European North West Shelf- Ocean Physics Hindcast performed by the Proudman Oceanographic Laboratory (POL), hereafter referred to as POL's hindcast [Holt et al., 2005]. This hindcast over 45 years (1960 - 2004) was performed with the Atlantic Margin Model, a coupled hydrodynamic-ecosystem model. Its hydrodynamics are supplied by the POL 3D baroclinic model (POL3DB) [Holt and James, 2001, Holt et al., 2001], which is part of the POL Coastal Ocean Modeling System, while the ecosystem component is supplied by the European Regional Seas Ecosystem Model [Blackford et al., 2004]. The model fully covers the northwest European continental shelf, its domain ranging from $20^{\circ} \mathrm{W}$ to $13^{\circ} \mathrm{E}$ and $40^{\circ} \mathrm{N}$ to $65^{\circ} \mathrm{N}$. The horizontal resolution is comparable to that of DCSM, $1 / 6^{\circ} \times 1 / 9^{\circ}$ in longitude and latitude, respectively. The model has 42 terrain-following coordinate levels in the vertical.

\section{MODELING LAT RELATIVE TO EGG08}

In this experiment LAT relative to EGG08 will be computed by forcing the model with astronomical tide and the average monthly variations in the meteorological forcing and steric forcing contributions. The LAT value per grid point is derived as the minimum modeled water level over the entire time series. The average monthly variations in the meteorological and steric contributions are computed by averaging for each calendar month, all available forcing fields over a period of 20 years (1984-2004). The obtained yearly time series have been used for the twenty year model run. In order to avoid jumps in the modeled water levels in the transition from month to month, the obtained time series are interpolated to 3-hourly values (the original temporal resolution of the meteo data) using a cubic spline interpolation. Here, we assigned the monthly means to the mid-epochs of each month. The meteorological and steric forcing contributions to the tidal water levels prescribed at the open sea boundaries are obtained in the same way as was used to derive the average monthly variations. For more details about the experimental setup we refer to Slobbe et al. [2012b].

The modeled LAT surface is shown in Fig. 1. Many of the features shown in this map are consistent with oceanographic expectations like coincidence of the locations where the modeled LAT values approaches zero with the well-known amphidromic system in the northwest European continental shelf. The minimum and maximum differences between the LAT surface obtained in this experiment and the one obtained using the original approach [Slobbe et al., 2012b, Experiment I] are -15.8 and $5.7 \mathrm{~cm}$, while the RMS is $5.5 \mathrm{~cm}$. The largest differences are observed west of the Danish coast.

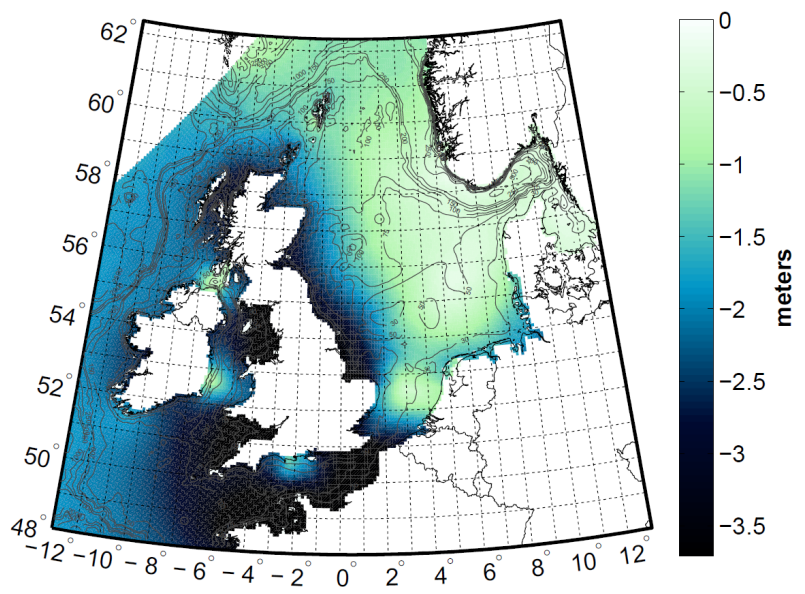

Figure 1: Lowest Astronomical Tide relative to EGG08 computed over the full simulation period January 1, 1984 - January 1, 2004. The grey lines in the map show the contour lines of the bathymetry. The data will be made publicly available by the Hydrographic Service of the Royal Netherlands Navy.

Validation

The obtained LAT surface is validated using LAT values at 92 onshore and 10 offshore tide gauges. Between 95 and 103 constituents are estimated depending on the station. The length of the time series varies between 2.5 years and 20 years. The set of constituents used to derive the observed LAT 
values is that set for which the RMS of the differences between the observed water levels and the reconstructed astronomical tide is lowest. The obtained differences between observed and modeled LAT reveal a mixture of errors in both model and observations. In Slobbe et al. [2012b], we found that systematic errors in the representation of the tidal amplitude dominate. After correction for all known systematic differences, the average difference between observed and modeled LAT equals -9.1 $\mathrm{cm}$ with minimum and maximum deviations of -53.6 and $15.1 \mathrm{~cm}$, respectively. Using the standard deviations of the differences between observed and modeled tidal minima, we performed a test to evaluate the statistical significance of these differences. For three stations, the observed differences are statistically significant at the $99 \%$ confidence level. These are located in the Irish Sea where DCSM representation is known to be lower than average. In Slobbe et al. [2012b], we also showed that the choice of the set of tidal constituents for each tide gauge has a significant influence on the estimated LAT value at this station. Whether the sets used in this study are a good choice is further investigated.

\section{THE SAFETY OF LAT AS A CHART DATUM ASSESSED}

Besides the fact that all predicted tidal water levels become positive in sign, another main motivation to use LAT as CD is that LAT provides an indication of the minimal water depth that can be expected under average meteorological conditions and hence provides a sense of safety. Indeed, any surface above LAT results in charted depths that are occasionally larger than the true depth, which might lead to a false sense of safety. However, it is well-known that meteorological conditions can result in water levels below LAT, especially in shallow waters. Hence, the sense of safety evoked by the use of LAT as $C D$ is only justified in case the probability that the instantaneous water level drops below LAT is low.

In this study, the probabilities that the minimum instantaneous water levels in periods of tidal minima are below LAT are computed using time series of the modeled instantaneous water levels. In Slobbe et al. [2012b], we show that in the eastern part of the North Sea, these probabilities appear to be in the order of once per month to once per week. As could be expected, these probabilities are largest in winter, followed by spring, fall and summer. The probabilities in winter and summer differ, approximately, half an order of magnitude. The varying probability that the water level is below LAT motivated us to propose a CD definition as the probability that the actual water level falls below the defined level. Without attempting to prescribe how large the probability should be, we realized CD using this approach for different probabilities and quantified the differences to LAT. As shown in Slobbe et al. [2012b], even for a probability of once per year, the probabilistic CD would be below LAT by several decimeters.

\section{CONCLUSION}

In this paper, we have modeled the LAT surface relative to the European Gravimetric Geoid 2008 (EGG2008) using the extended and vertically referenced DCSM model. The data will be made publicly available by the Hydrographic Service of the Royal Netherlands Navy. In addition, we performed an assessment of the suggested sense of safety of the LAT Chart Datum.

A comparison of the obtained LAT surface with the one obtained using the original approach reveals significant large differences. The obtained differences between observed and modeled LAT reveal a mixture of errors in both model and observations. Significant improvements are expected when the successor of the DCSM version 5 model is used. DCSM version 6 provides a much better representation of the tide due to, amongst others, increased spatial resolution and incorporation of more physics.

From our experiment aimed to investigate whether the sense of safety evoked by using LAT as CD is justified, we conclude that this is not the case; in the eastern part of the North Sea we found that actual water level drops below LAT during periods of tidal minima once per month to once per week. The results suggest that a probabilistic CD definition better suits practical needs. Such a definition has 
the additional advantages that it offers an opportunity to realize CD unambiguously and is much easier to validate.

\section{REFERENCES}

Blackford, J., J. Allen, and F. Gilbert. Ecosystem dynamics at six contrasting sites: a generic modelling study. J. Marine Syst., 52(1-4):191-215, 2004. ISSN 0924-7963. doi: 10.1016/j.jmarsys.2004.02.004.

Dee, D. P., S. M. Uppala, A. J. Simmons, P. Berrisford, P. Poli, S. Kobayashi, U. Andrae, M. A. Balmaseda, G. Balsamo, P. Bauer, P. Bechtold, A. C. M. Beljaars, L. van de Berg, J. Bidlot, N. Bormann, C. Delsol, R. Dragani, M. Fuentes, A. J. Geer, L. Haimberger, S. B. Healy, H. Hersbach, E. V. Hólm, L. Isaksen, P. Kållberg, M. Köhler, M. Matricardi, A. P. McNally, B. M. Monge-Sanz, J.-J. Morcrette, B.-K. Park, C. Peubey, P. de Rosnay, C. Tavolato, J.-N. Thépaut, and F. Vitart. The ERAInterim reanalysis: configuration and performance of the data assimilation system. QJ Roy. Meteor. Soc., 137(656):553-597, 2011. ISSN 1477-870X. doi: 10.1002/qj.828.

Denker, H., J.-P. Barriot, R. Barzaghi, D. Fairhead, R. Forsberg, J. Inde, A. Kenyeres, U. Marti, M. Sarrailh, and I. Tziavos. The Development of the European Gravimetric Geoid Model EGG07. In F. Sans ' $O$ and M. G. Sideris, editors, Observing our Changing Earth, volume 133 of International Association of Geodesy Symposia, pages 177-185. Springer Berlin Heidelberg, 2008. ISBN 978-3-54085426-5. doi: 10.1007/978-3-540-85426-5 21.

Dodd, D. and J. Mills. Ellipsoidally referenced surveys: issues and solutions. Int. Hydrogr. Rev., (6):19-29, 2011.

FIG Commission 4 Working Group 4.2. FIG Guide on the Development of a Vertical Reference Surface for Hydrography. Technical Report 37, The International Federation of Surveyors (FIG), Frederiksberg, Denmark, 2006.

Gerritsen, H., H. de Vries, and M. Philippart. The Dutch Continental Shelf Model. In D. R. Lynch and C. N. K. Mooers, editors, Quantitative Skill Assessment for Coastal Ocean Models, Coastal Estuarine Stud., volume 47, pages 425-467. AGU, Washington, D. C., 1995.

Holt, J. T., and I. D. James. An s coordinate density evolving model of the northwest European continental shelf, 1, Model description and density structure. J. Geophys. Res., 106:14015-14034, 2001. doi: 10.1029/2000JC000304.

Holt, J. T., I. D. James, and J. E. Jones. An s coordinate density evolving model of the northwest European continental shelf, 2, Seasonal currents and tides. J. Geophys. Res., 106:14035-14054, 2001. doi: $10.1029 / 2000 J C 000303$.

Holt, J. T., J. I. Allen, R. Proctor, and F. Gilbert. Error quantification of a high-resolution coupled hydrodynamic ecosystem coastal ocean model: Part 1 model overview and assessment of the hydrodynamics. J. Marine Syst., 57(1-2):167-188, 2005. ISSN 0924-7963. doi: 10.1016/j.jmarsys.2005.04.008.

International Hydrographic Organization. Resolutions of the International Hydrographic Organization. available at www.iho.int, 2011b. Publication M-3, 2nd ed., 2010, Updated to August 2011.

IOC, SCOR and IAPSO. The international thermodynamic equation of seawater - 2010: Calculation and use of thermodynamic properties, 2010. Intergovernmental Oceanographic Commission, Manuals and Guides No. 56, UNESCO (English), 196 pp. Available online at: http://www.teos-10.org/pubs/TEOS10 Manual. pdf (accessed September 29, 2011). 
Leendertse, J. J. Aspects of a Computational Model for Long-period Water-wave Propagation. Rand Corporation, Santa Monica, 1967.

Slobbe, D.C., M. Verlaan, R. Klees, and H. Gerritsen. Obtaining instantaneous water levels relative to a geoid with a 2D storm surge model. Submitted, 2012a.

Slobbe, D.C., R. Klees, M. Verlaan, L.L. Dorst, and H. Gerritsen. Lowest Astronomical Tide in the North Sea derived from a vertically referenced shallow water model, and an assessment of its suggested sense of safety. Submitted to Marine Geodesy, 2012b.

Simon. B., Niveaux caractéristiques et coefficient de marée: calcul direct à l'aide des constantes harmoniques, volume 2 of Rapport d'étude - Service hydrographique et océanographique de la marine. Service hydrographique et océanographique de la marine, Paris, FRANCE, 2001.

G. S. Stelling. On the construction of computational methods for shallow water flow problems. PhD thesis, Delft University of Technology, Delft, 1984. Rijkswaterstaat Communications 35.

J. F. Turner, J. C. Iliffe, M. K. Ziebart, C. Wilson, and K. J. Horsburgh. Interpolation of Tidal Levels in the Coastal Zone for the Creation of a Hydrographic Datum. J. Atmos. Ocean. Tech., 27:605-613, 2010. doi: 10.1175/2009JTECHO645.1.

M. Verlaan, A. Zijderveld, H. de Vries, and J. Kroos. Operational storm surge forecasting in the Netherlands: developments in the last decade. Philos. Trans. Royal Soc. Math. Phys. Eng. Sci., 363:1441-1453, 2005. doi: 10.1098/rsta.2005.1578.

\section{BIOGRAPHIES}

Cornelis Slobbe is a Dutch Geodetic Engineer from the Delft University of Technology. He currently works at a PhD-project at Delft University of Technology that aims to develop a procedure that enables to derive a consistent set of vertical reference frames. He also participates in the EU Interregion IVB project BLAST.

Martin Verlaan studied applied mathematics at the University of Twente and obtained his PhD at Delft University in 1997 on the topic of data-assimilation for storm surge forecasting. He is currently working at Deltares and TU Delft. His research interests are data-assimilation and operational forecasting of sealevel and waves. He is involved in the EU research projects: Jerico, MyWave and Sangoma. During storms he works for the Storm Surge Warning Service in the Netherlands (SVSD).

Leendert Dorst is a Dutch Geodetic Engineer from the Delft University of Technology. He is employed at the Netherlands Hydrographic Service as Head of the Department Geodesy \& Tides. In 2009, he obtained a PhD degree from the University of Twente, on the estimation of sea floor dynamics using time series of bathymetric surveys, to improve the resurvey policy of the Netherlands.

Herman Gerritsen studied applied mathematics at the University of Twente and obtained his PhD at Twente in 1982 on the topic of accurate boundary forcing in tidal flow modeling. He is currently working at Deltares. His research interests are data-assimilation and methodologies for quality assessment of numerical models and their use.

\section{CONTACT DETAILS}

D.C. Slobbe (Delft University of Technology)

PO Box 5048, Delft, The Netherlands

Tel.: +31 15 2784543, Email: D.C.Slobbe@tudelft.nl 